\title{
Posso contar uma história?
}

\section{Joseane Maia Santos Silva ${ }^{1}$}

\section{Era uma vez...}

uma professora de literatura infantojuvenil em estado de euforia mediante a aceitação, como aluna

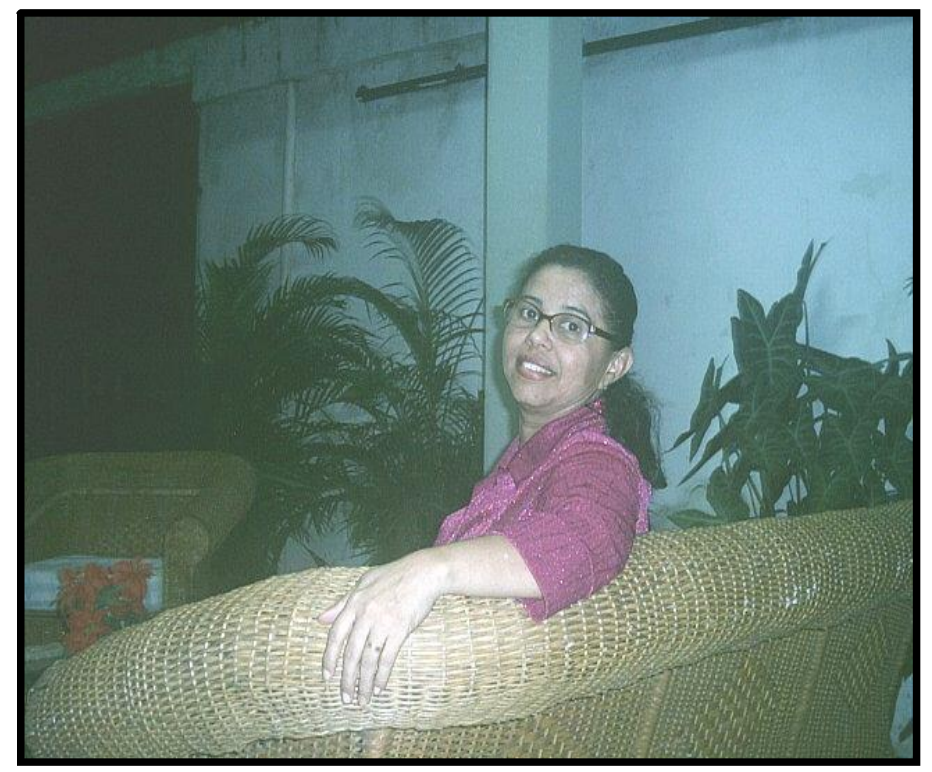
especial, em agosto de 2005, pela Dra. Lúcia Pimentel Góes, no Programa de Pós-Graduação da USP, na área de Estudos Comparados em Literaturas de Língua Portuguesa. Família de acordo com a ida para São Paulo, o encontro com essa cidade foi muito diferente dos outros porque, dessa vez, não estava ali 'por uns dias', iria 'morar' durante alguns meses, portanto, era urgente buscar alguns conhecimentos básicos que permitissem locomoção, visitas a livrarias, museus, teatros e, principalmente, a sebos (considerados verdadeiros garimpos), onde as visitas foram tão freqüentes que, inúmeras vezes, as informações sobre determinados livros, dificeis de encontrar, foram dadas pela nordestina recém-chegada à cidade, porém com tempo de sobra para andar, estudar e sentir saudades da terrinha onde canta o sabiá...

Entre um susto e outro, entre um encanto e outro, e o desejo de voltar, dois desafios se impuseram: vencer o medo de uma cidade tão singular e passar no seletivo para resolver a vida acadêmica. O primeiro 
foi enfrentado andando muito a pé, de ônibus, até formar um mapa na cabeça (incompleto, é claro!) e o segundo, estudando, exaustivamente, ao mesmo tempo em que elaborava o pré-projeto aprovado em 2006.

\section{Como um projeto sobre...}

O projeto inicial sobre fábulas foi modificado para a pesquisa sobre narrativas orais, após leitura do fascículo Quilombolas de Caxias do Maranhão, do Projeto Nova Cartografia Social da Amazônia, ${ }^{2}$ que resume a situação histórica e social de dezesseis comunidades remanescentes de escravos, além de trazer um mapa e fotos de homens, mulheres, casas e paisagens. Uma foto de duas crianças dançando baião no lugar denominado Quilombo Mandacaru dos Pretos dava a momentânea impressão de que via in loco a dança se concretizando como quando olhamos imagens em terceira dimensão. Aquela cena mostrava o zelo das comunidades pela própria história e cultura, como forma de resistência à onda globalizada das danças sensuais modernas.

Portanto, o estudo sobre essas narrativas orais, confrontadas com narrativas escritas divulgadas em lingua portuguesa, no Brasil, em obras de autores contemporâneos, objetiva verificar a função social, analisar o sentido estético, numa visão integradora, distinguindo aspectos simbólicos, sociais e ideológicos, enfim, destacar o papel dessas narrativas para aquelas comunidades. Isso implica estudar seus enredos e estética, buscar razões por que são lembradas, de modo que dados sobre o homem e a mulher quilombolas tornem-se compreendidos, porque dessa compreensão avulta a idéia de cultura como um sistema de significados.

\section{Então...}

De volta a Caxias-MA, a visita ao povoado Lavras, em agosto de 2007, para os primeiros contatos, mostrou moradores arredios, sem muito interesse em conversar sobre suas vidas, a não ser que se apresente... 


\section{Em companhia dos representantes das comunidades...}

No Centro de Estudos Superiores de Caxias-Universidade Estadual do Maranhão, dia 19 de setembro de 2007, foram dadas as explicações sobre a pesquisa, para Rosa Maria Barroso da Conceição, Manoel Moura da Silva e João Batista da Rocha Santos, membros da ACONERUQ-Associação de Comunidades Negras Rurais Quilombolas de Maranhão e moradores dos povoados Olho D’Água do Raposo, Jenipapo e Gameleira, respectivamente, que se colocaram imediatamente à disposição durante o tempo que fosse necessário, ficando para depois o acerto da primeira visita. Inúmeros compromissos desses representantes, em São Luís e em Brasília, para resolver questões das comunidades de Caxias, inviabilizaram a primeira visita antes do final de 2007. Pelo relato dos três, ficou claro que suas atuações extrapolam a questão do simples reconhecimento da condição de remanescentes de quilombolas, sendo um engajamento que visa a regularização das associações quilombolas, o processo de identificação e mapeamento das comunidades.

É importante esclarecer que a questão dos remanescentes de quilombolas maranhenses insere-se na história do Centro de Cultura Negra do Maranhão, criado em 1979, entidade que desenvolve projetos e realizou vários encontros com vistas a ações de formação para os afrodescendentes perceberem-se como sujeitos históricos, capazes de modificar a realidade de opressão em que vivem; e que, passadas quase duas décadas da publicação da Constituição Federal de 1988 e quatro anos da publicação do Decreto $n^{\circ} 4.887 / 2003$, que regulamenta o processo de identificação, reconhecimento, demarcação e titulação das terras ocupadas por remanescentes das comunidades de quilombolas, atualmente, a luta continua nos âmbitos jurídico e educacional.

\section{Mas no quilombo Jenipapo...}

Dia 28 de janeiro do ano em curso, a produtiva visita à zona rural, onde residem 32 famílias, rendeu duas entrevistas: uma com o Sr. José Correia (Zé Correia), de 71 anos, e outra com o Sr. Raimundo 
José da Silva (Raimundo Geraldo, por causa do pai), de 77 anos, em que ambos falaram sobre um mito universal - o lobisomem - também conhecido no Nordeste como capelobo, descrito como um homem pequeno, umbigo cabeludo e cabeça pelada. Sr. Raimundo também lembrou da infância, de histórias de cativeiro contadas pela mãe e, lamentando o pouco interesse das pessoas em falarem sobre o assunto, afirmou que ninguém hoje num acha mais quem conte história, porque hoje tão tudo civilizado, num quer mais contar feiúra. A minha mãe contava muita coisa que acontecia pra nós.

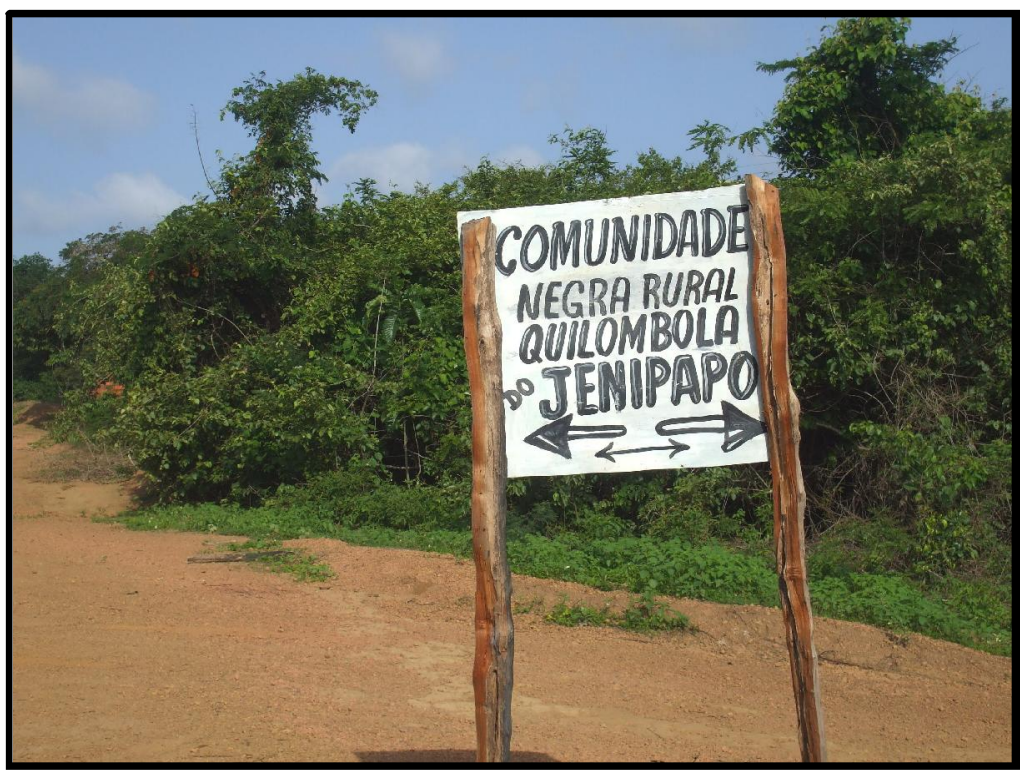

Foto da autora

\section{O Sr. Francisco de Assis dos Santos (conhecido por Diá)...}

No Jenipapo, dia 09 de fevereiro, em entrevista revelou-se, aos 61 anos, conhecedor de um vasto repertório de estórias e muito consciente, politicamente, quando descreveu a luta empreendida pelas comunidades negras rurais: 


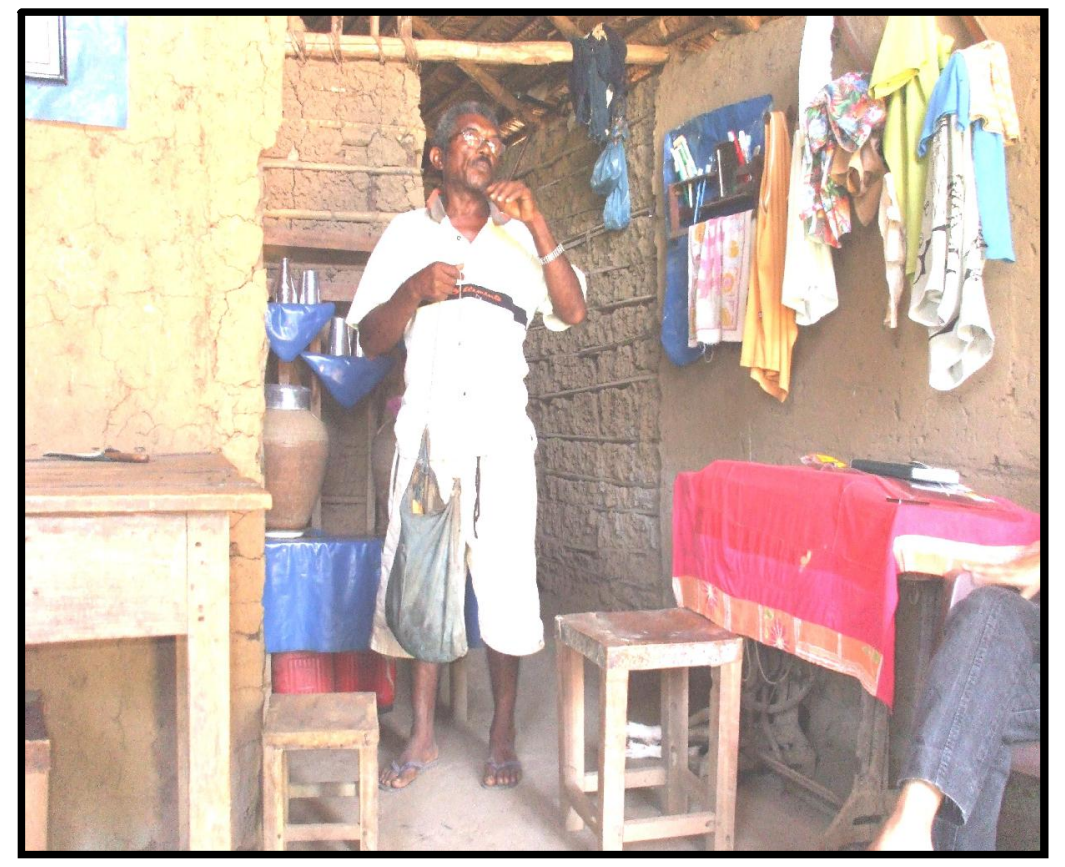

Seu Diá (foto da autora)

Então... o povo tem na cabeça que mudou e eu tenho na cabeça que nada mudou, a questão racial, o povo diz, mudou. Não tá mudando nada, a questão racial não é a chave... não é a chave. A chave

é a questão social... não é a racial. Na questão social você pode ser arvo da cor de leite, do jeito que for, se você não for nada não tem direito a nada, se você é preto e já tem uma condição, você tem um privilégio. Onde é que tá a questão? É social.. é social.... Agora essa questão é muito mais difícil de ser resolvida...

\section{Quanto à D. Clarice Maria da Conceição...}

Moradora mais idosa da comunidade, conhecida como D. Binoca, aos 79 anos, mostrou-se bastante animada para falar de lobisomem e de alma penada como fato e não como causo, pois os acontecimentos que envolveram irmão, filho e sobrinho foram relatados com riqueza de detalhes, descrição de lugares e justificativa. Para ela, o lobisomem é 
gente que vira bicho porque diz que era malfeitoria que ele fazia, às vezes matava gente, brigava com o pai com a mãe. Isso tudo de primeiro tinha.

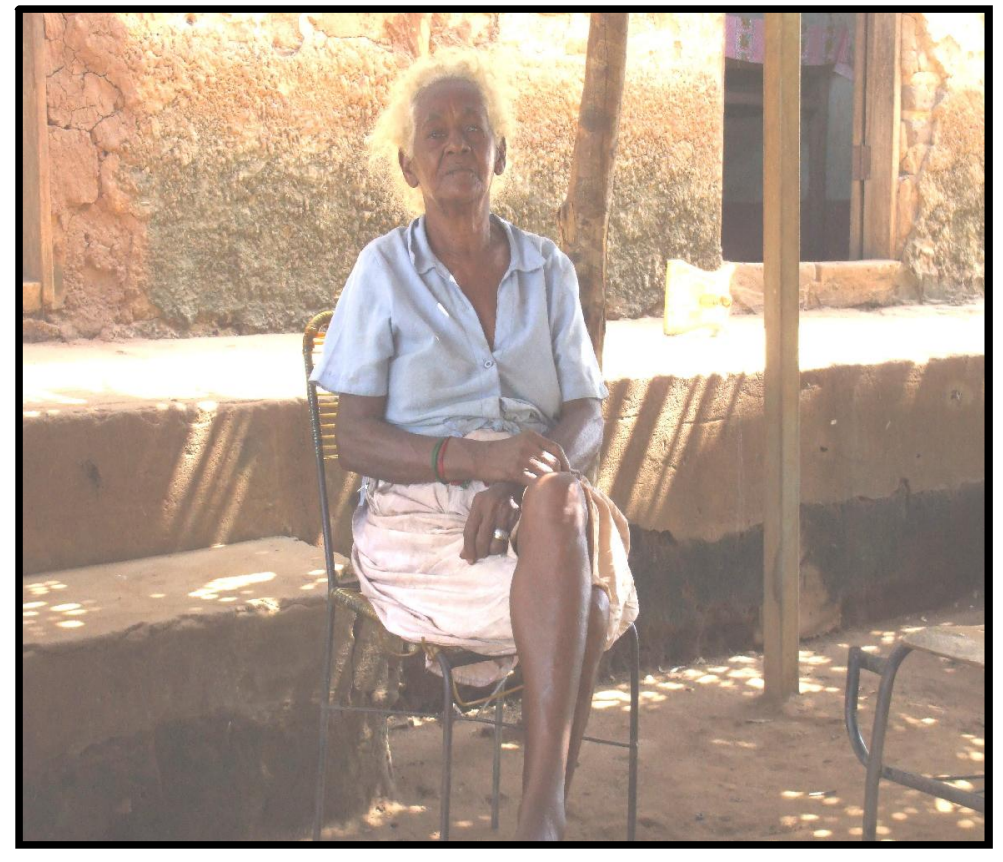

Dona Clarice (foto da autora)

\section{E no mesmo dia, no quilombo Mandacaru dos Pretos...}

As entrevistas aconteceram numa roda de conversas, embaixo de uma mangueira, com o Sr. Francisco Nunes de Almeida, de 44 anos, que se mostrou exímio narrador, ao emendar uma estória após outra, apresentando causos de caçador, de contratos com a morte, de animais e objetos falantes, no melhor estilo das fábulas; quanto ao Sr. Antonio Paulino dos Santos, de 68 anos, líder da comunidade, contador de estórias de botija e de contrato com a morte, fez um relato minucioso da luta empreendida com um fazendeiro que, ao cercar as terras, incluiu bens considerados valiosos como o cemitério de seus ancestrais e um cacimbão. Conforme palavras dele:

...o cemitério continua dentro da terra dele, meus pais, os troncos velhos ta lá dentro enterrado... o cacimbão também, tenho fé em Jesus que Deus não vai deixar eu morrer antes de libertar ele, pra isso eu to trabaiando em cima disso... Deus vai 
me segurar mode ver se eu consigo libertar esse cacimbão. Por que que eu digo essas palavras pra senhora? Porque quando Deus me colocou nessa terra a primeira água que eu bebi foi desse lugar, não só eu como muitos... é uma água mineral, água boa...

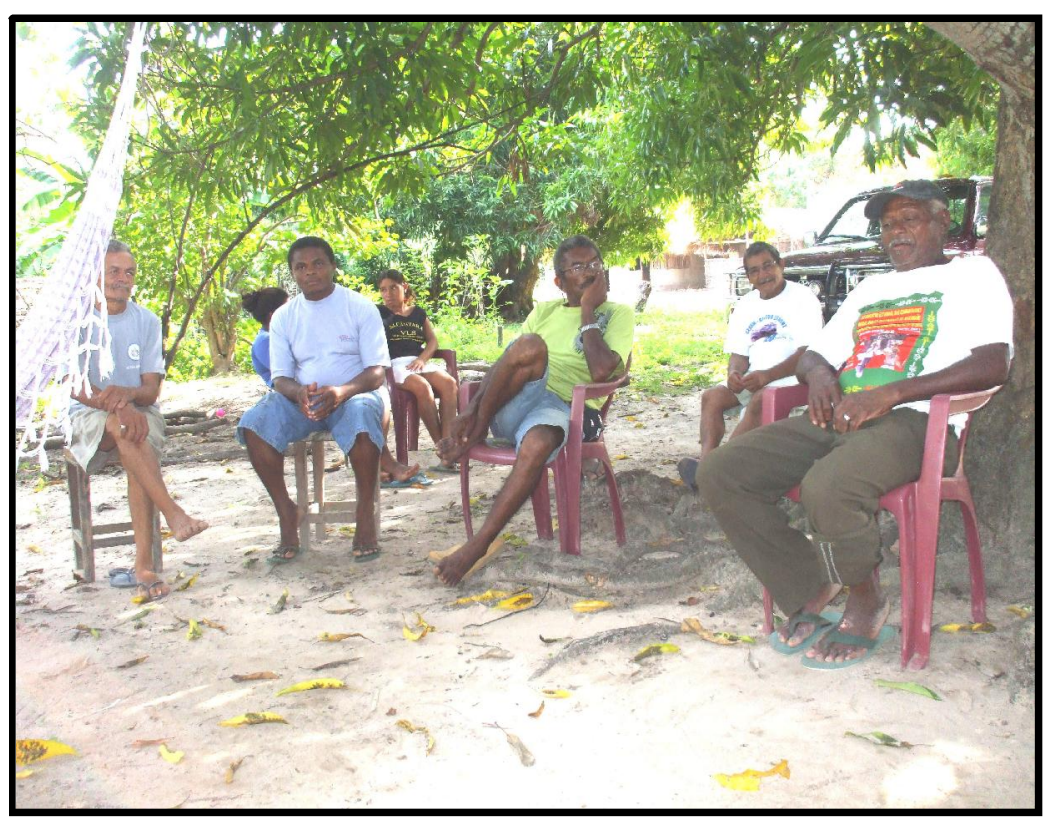

Foto da autora

As mulheres, embora arredias a principio, depois se revelaram boas contadoras de estórias, como D. Aldeci de Góes Bezerra, de 51 anos, a primeira a falar de Camonge, corruptela de Luís Vaz de Camões, transformado numa figura mítica pelo inventivo imaginário popular e, conseqüentemente, personagem facilmente encontrado na literatura de cordel em que mostra astúcia e irreverência; D. Rita Nunes, de 43 anos, quebradeira de coco, apontada pelas companheiras como tendo amplo repertório, contou apenas uma estória sobre a mulher que traía o marido; e D. Joaquina Eduarda da Silva, de 56 anos, contou a estória de um tesouro escondido como se fosse fato, dando nome às pessoas e aos lugares, reforçando ao final: ... e aí foi logo, logo, o Dora melhorou de vida, comprou carro, e inté hoje ele vive bem.. isso foi verdade...

Foi verdade essa história que acabei de contar, quem quiser que conte outra... 
Caxias, 05 de março de 2008.

1 Doutoranda em Estudos Comparados de Literaturas de Língua Portuguesa, FFLCH-USP. Pesquisa: Tecendo estórias das comunidades negras rurais quilombolas aqui e acolá (título provisório). E-mail:joseanemssilva@yahoo.com.br

2 Desenvolvido em parceria com a Associação de Comunidades Negras Rurais Quilombolas do Maranhão-ACONERUQ, Sob a Coordenação de Alfredo Wagner Berno de Almeida, com a colaboração da equipe de pesquisa da Prof ${ }^{a}$ Arydimar Vasconcelos Gaioso e universitários dos cursos de História e Geografia do Centro de Estudos Superiores de Caxias-Universidade Estadual do Maranhão, elaborado durante a Oficina de Mapas das Comunidades Quilombolas de Caxias, em março de 2006. 